\title{
Myopic Shift during Hyperbaric Oxygenation Attributed to Lens Index Changes
}

Knut Evanger, MSc, Barbara K. Pierscionek, PhD, Guro Vaagbø, MD, Einar Thorsen, MD, PhD, and Olav H. Haugen, MD, $\mathrm{PhD}$

Institute of Clinical Medicine, University of Bergen, Bergen, Norway (KE, OHH), Faculty of

Science Engineering and Computing, Kingston University, Kingston-upon-Thames, United

Kingdom (BKP), Hyperbaric Medicine Unit, Department of Occupational Medicine, Haukeland

University Hospital, Bergen, Norway (GV, ET), Department of Clinical Science, University of

Bergen, Bergen, Norway (, ET), and Department of Ophthalmology, Haukeland University

Hospital, Bergen, Norway $(\mathrm{OHH})$

Short title: Hyperbaric Oxygenation Myopia Attributed to Lens Index Changes

3 tables; 2 figures

Received: ; accepted May 21, 2015. 


\begin{abstract}
Purpose. To examine ocular lens parameters and structural changes in order to elucidate mechanisms underlying the myopic shift and cataract-related changes that occurs in some patients during hyperbaric oxygen (HBO) therapy. Methods. Scheimpflug images (Nidek EAS1000) of the crystalline lens, measurements of scattered light, objective refraction, keratometry, tonometry and axial length of the eye were obtained after the first day of HBO therapy, and repeated when patients had completed 19 days of the treatment. Results. Significant reduction in mean optical density was found in the lens nucleus, $-2.8 \pm 4.3$ units $(\mathrm{p}=0.009)$ and $-2.2 \pm 4.1$ units $(\mathrm{p}=0.027)$ within circular and oval areas, respectively. Significant decrease in mean backward scattered light was measured, $-0.4 \pm 0.8$ units $(\mathrm{p}=0.022)$. Mean myopic shift was $-0.58 \pm 0.39 \mathrm{D}(\mathrm{p}<0.001)$, while cortical optical density, forward scattered light, lenticular parameters, keratometry, tonometry, anterior chamber depth and axial length of the eye appeared unchanged. Conclusions. Transient myopic shift reported in patients during HBO therapy is attributed to changes in the refractive index of the lens. No changes in lens curvatures or thickness were found after treatment.
\end{abstract}

Key words: hyperbaric oxygen, myopic shift, nuclear cataract, optical density, scattered light 
The crystalline lens is an avascular transparent organ and under normal physiological conditions embedded in a low oxygen environment. During hyperbaric oxygen (HBO) therapy in a monoplace chamber, the patient is surrounded by pure oxygen at a pressure higher than atmospheric. The monoplace chamber compresses one patient at a time, placed in a supine position. Breathing oxygen at high pressure increases the transfer of oxygen from blood to tissue in an attempt to revitalize oxygen-dependent metabolism in ischemic body tissue. HBO therapy is a commonly used medical treatment in a variety of human diseases, including radiationinduced osteonecrosis, proctitis and cystitis following previous cancer therapy.

A temporary myopic shift has often been described in patients treated with HBO therapy ${ }^{1-6}$ In a previous article, we reported that the myopic shift was caused by changes in the crystalline lens because the refractive changes appeared only in phakic and not in pseudophakic eyes. ${ }^{5}$ Changes in other optical refractive elements of the eye did not explain the degree of the myopic shift. ${ }^{4-6}$ The myopic shift appears to be fully reversible within 10 weeks after completion of the treatment. ${ }^{6}$

To achieve high quality of vision, the crystalline lens must allow for the unimpeded passage of light and provide sufficient refractive power to focus a sharp image on the retina. The refractive index is determined by the concentration of lens proteins, ${ }^{7}$ the composition and distribution of which influence the amount of light scatter, absorption and transmission through the lens tissue. Formation of nuclear cataract has been observed in a patient after a standard course of therapeutic $\mathrm{HBO},{ }^{8}$ and oxidative stress causing damage to lens components is proposed to play 
an important role. ${ }^{9}$ Development of nuclear cataract is reported after extended periods of HBO exposure in patients with initially clear lenses before the start of treatment. ${ }^{10}$

The visual side effect of HBO therapy is reported to be a cumulative process, ${ }^{5,11}$ and each daily treatment session is of equal oxygen load and duration. Changes in lenticular transparency may therefore take place long before any changes of the lens are clinically detectable by slitlamp examinations. ${ }^{11}$ Any explanation of the mechanism causing the refractive changes must also take into account that both significant myopic shifts ${ }^{1-6}$ and hypermetropic shifts ${ }^{12,13}$ may occur in patients treated with HBO therapy.

The present study was undertaken to examine lens surface curvatures, axial thickness and structural changes in order to elucidate the mechanisms underlying the myopic shift and cataractrelated changes that occur in some patients during hyperbaric oxygen therapy. Ocular refraction, central corneal radius, intraocular pressure, anterior chamber depth and axial length of the eye were additionally monitored to verify if these variables were consistent with previously reported values.

\section{MATERIALS AND METHODS}

Patients referred to Haukeland University Hospital for elective HBO therapy were invited to take part in the study as they presented for the treatment. Twenty patients (10 males and 10 females) with a mean age of $56.0 \pm 7.7$ years, (age range 44 to 68 years) met the inclusion criteria, and attended the daily scheduled HBO sessions without interruptions. All had treatment for radiationinduced osteonecrosis, proctitis or cystitis. All the patients were of Caucasian origin. 
The protocol was approved by the Regional Ethics Committee and the Norwegian Data Inspectorate. Eye examinations were performed with the full understanding and written consent of each patient, according to the tenets of the Declaration of Helsinki for research involving human subjects. Inclusion criteria were age below 70 years, normal ocular health and a spectacle prescription within $\pm 5.00 \mathrm{D}$. None of the patients had visual complaints or any subjective reduction in visual acuity. Those with HBO therapy during the past 12 months, radiotherapy of the orbit, corneal refractive surgery or any wearing of contact lenses were excluded to avoid effects on corneal curvature. All measurements were conducted by the same investigator (KE) to avoid inter-examiner bias.

HBO therapy was given once daily for 20 days, five days a week in accordance with the standard protocol. ${ }^{5}$ The patients were compressed with oxygen in a monoplace hyperbaric chamber to a total pressure of $240 \mathrm{kPa}$ over a period of 10-15 minutes. $100 \%$ oxygen was breathed at this pressure for 90 minutes, in three cycles of 30 minutes, interrupted by breathing compressed air from an oronasal mask for five minutes between the cycles. After each treatment session, the patients were decompressed to normal atmospheric pressure in 7-10 minutes.

The eye examination consisted of objective refraction, keratometry, measurements of forward scattered light, intraocular pressure, axial length of the eye, Scheimpflug pictures (lens optical density, lens surface curvatures, anterior chamber depth, axial lens thickness, pupil diameter), and backward scattered light. A routine eye examination with the slitlamp biomicroscopy and ophthalmoscopy was also undertaken. Patients arrived to the hospital late in the afternoon the day before, or in the morning on the day they started the HBO therapy. There was no time to 
perform the eye examination before the patients entered the chamber on the first day of treatment. For this reason baseline measurements were performed in the afternoon after completion of the first session of HBO therapy (day 1). Follow-up measurements were repeated in identical sequences within the same hour of the day when the patients had completed 19 days of the regular treatment.

Objective refraction and keratometry were assessed with the Nidek ARK 900 autorefractor/keratometer (Nidek Co., Ltd., Gamagori, Japan). Refractive changes measured with this instrument through an undilated pupil have previously shown high correlations both between the right and left eye and with subjective refraction ${ }^{5}$. Hence, in the present study, the subsequent measurements and data comparisons were taken from the right eye only.

Forward scattered light was measured with the C-Quant straylight meter (Oculus Optikergeräte, Germany), which is based on the compensation comparison method. ${ }^{14-16}$ The patient focuses with one eye on the circular test field, which is divided into a right and a left semicircle. Compensating light is randomly presented in one of the two semicircles. A number of short stimuli are presented during the test, and the patient activates the corresponding right or left push button depending on which of the two semicircles flickers more intensely. A logarithmic straylight parameter value ( $\log [\mathrm{s}]$, base 10$)$ is established for the C-Quant, and determines the ratio between the scattered light and the non-scattered light. With $\log [\mathrm{s}]$ notation, the straylight value changes linearly. Equal differences in $\log [\mathrm{s}]$ correspond to equal differences in s ratio, and an increase of 0.3 correlates with a doubling of the amount of straylight. An average $\log [\mathrm{s}]$ value for young healthy eyes is around $0.9 .{ }^{15}$ Quality parameter $\mathrm{Q} \geq 1.0$ and Estimated Standard 
Deviation $(\mathrm{ESD}) \leq 0.08$ were used as limits for reliable measurements. ${ }^{14}$ An ICare Rebound tonometer (Tiolat Oy, Helsinki, Finland) was applied to monitor intraocular pressure. ${ }^{17}$

All the above-mentioned examinations were performed through undilated pupils. Due to logistical considerations and in order to reduce patients waiting time, mydriatic eye drops were administered before the patients moved to complete the measurements in another laboratory. The final examinations included Scheimpflug imaging, which require a wide open pupil. A minimum $4 \mathrm{~mm}$ diameter pupil is required for backward scattered light assessment. ${ }^{18}$ Axial length of the eye was measured before the Scheimpflug imaging as the instrument was located in the same room and can be used both with and without pupil dilatation. Table 1 show all measurements listed in the order taken.

Axial length of the eye was measured with the IOLMaster (Carl Zeiss Meditec, Jena, Germany) and displayed as the distance from the anterior cornea to the vitreo-retinal interface. A Nidek Model EAS-1000 anterior segment analysis system (Nidek, Gamagori, Japan) was used to measure optical density of the lens, lens surface curvatures, anterior chamber depth and axial lens thickness. The system is based on computer analysed photographs captured according to the Scheimpflug principle ${ }^{19,20}$ in combination with slit lamp illumination. Two Scheimpflug pictures were taken at the same conditions before and after HBO therapy. A vertical slit beam of $0.08 \times 14$ $\mathrm{mm}$, with wavelength $880 \mathrm{~nm}$ and flash level of $200 \mathrm{Ws}$ was projected into the eye. Backward scattered light is produced when the slit beam passes through the lens and is captured by a Charged Couple Device (CCD) camera at the temporal side at an angle of $45^{\circ}$ to the slit beam optical axis. ${ }^{20}$ From a well-focussed cross-sectional picture of the lens displayed on a LED 
monitor (screen resolution 1920 x 1080), biometrical data of the anterior segment was analyzed with the EAS-1000 computer software (version 1.23E). Backward scattered light was analyzed in the "Densitometry" program, and measured as optical density. A point just in front of the anterior lens capsule (defined as density $=0$ ) was chosen and compared with the density values at different locations within the lens. Subsequent points along the central optical axis line within the anterior sub-capsular region were measured. Average optical density was measured within oval areas (40 x15 pixels) in the anterior and the posterior cortex (Figure 1A). In the lens nucleus, average optical density was measured within both circular areas ( $35 \times 35$ pixels), and oval areas ( 75 x 35 pixels). The density measurement were graded in $256(0-255)$ pixel grayscale instrument specific units. ${ }^{21}$

Lens surface radius was examined in the "Axial Biometry" program by placing the cursor on three intersecting points along the curvature of the anterior surface and the posterior surface of the lens (Figure 1B). Anterior chamber depth was examined by placing the cursor along the optical axis, and displayed as the distance between the intersection points at the posterior cornea and anterior apex of the lens (one pixel equals about $0.026 \mathrm{~mm}$ ). ${ }^{21}$ Axial thickness of the lens was measured along the optical axis (Figure 1C). The pupil diameter was measured as the largest vertical edge-to-edge distance, in order to verify size of the pupil during dilatation.

Backscattered light was captured with the Lens Opacity Meter 701 (Interzeag, Schlieren, Switzerland). This instrument projects a cylindrical light beam of $1.5 \mathrm{~mm}$ in diameter and with wavelength $700 \mathrm{~nm}$ into the eye directed along the optical axis. A photometer detects changes in backscattered light at a fixed angle of $27^{\circ}$ below the incident beam. Lens Opacity Meter provides 
a quantitative measure of the degree of opacification in the axial part of the lens on a numerical scale in instrument specific units from 0 (clear lens) to 99 (dense cataract). ${ }^{18,22}$

Both the backscattered light measurements and the Scheimpflug pictures were made 40 minutes after administration of cyclopentolate $1 \%$ eye drops and in a dark room with only illumination from the instrument available. A pupil diameter of $6.00 \mathrm{~mm}$ or larger was achieved in all patients both at baseline and at the follow-up visits. The posterior section of the lens appeared visible in six of the 20 patients on the Scheimpflug pictures.

Lens refractive power was calculated using the Gullstrand-Emsley relaxed eye indices of refraction, ${ }^{23}$ together with the lens curvatures and lens thickness acquired from the Scheimpflug images. The lens surface power was obtained from the equation:

$$
F=(1.416-4 / 3) / r
$$

Here $F$ is the power of the lens surface, and $r$ is the absolute value of the radius. These parameters were implemented into the customary thick lens formula:

$$
L P=F_{1}+F_{2}-t / n F_{1} F_{2}
$$

in which $L P$ is the equivalent lens power, $F_{1}$ and $F_{2}$ are the anterior and posterior lens surface powers, $t$ is the lens thickness (in metres), and $n$ is the refractive index of the lens (1.416).

\section{Statistics}

The objective refractive state values were converted into spherical equivalent refraction (sphere power $+1 / 2$ of the cylinder power) as provided by the auto-refractor/keratometer and applied in 
the refractive change analysis. A Students paired $t$-test was used for comparison of ocular variables measured at the initial eye examination and the follow-up visit. Mean values are given together with standard deviation (mean $\pm \mathrm{SD}$ ), median, minima and maxima. Data analyses were conducted using the SPSS for Windows 22.0 program (2013). All probabilities quoted are twosided and statistical significance was taken as $\mathrm{p}<0.05$.

\section{RESULTS}

\section{Refractive Changes}

A significant mean myopic shift occurred for the full sample of 20 patients during treatment, $-0.58 \pm 0.39 \mathrm{D}($ ranged $0.00 \mathrm{D}$ to $-1.50 \mathrm{D})(\mathrm{p}<0.001)$. The refractive changes were mainly found in the spherical component. Eighteen of the eyes showed shifts in astigmatism with cylinder power $\leq 0.25 \mathrm{D}$, but there were no changes in total cylinder power greater than $0.50 \mathrm{D}$. For the six patients for whom the posterior lens surface data were available (Table 2), a significant mean myopic shift of $-0.65 \pm 0.48 \mathrm{D}$ (ranged $0.00 \mathrm{D}$ to $-1.50 \mathrm{D})(\mathrm{p}=0.022)$ was found. The median myopic shift was $-0.63 \mathrm{D}$ in both populations.

\section{Forward Scattered Light}

Forward scattered light showed no significant changes from before to after HBO therapy, -0.02 $\pm 0.15 \log [\mathrm{s}]$ units. 


\section{Ocular Biometry}

No significant differences in mean central corneal radius $(-0.01 \pm 0.03 \mathrm{~mm})$, intraocular pressure $(-0.7 \pm 1.8 \mathrm{mmHg})$, axial length of the eye $(0.00 \pm 0.02 \mathrm{~mm})$ and anterior chamber depth $(0.01 \pm$ $0.02 \mathrm{~mm}$ ) were measured.

\section{Lens Optical Density}

There was a decrease in lens optical density after HBO therapy compared to before therapy. The nucleus showed a significant reduction in mean optical density after treatment of $-2.8 \pm 4.3$ units (range -12.0 units to 4.5 units) $(\mathrm{p}=0.009)$ within the circular areas, and $-2.2 \pm 4.1$ units (range -10.5 units to 4.5 units $)(\mathrm{p}=0.027)$ within the oval areas (Table 2). Changes in mean optical density within the anterior and posterior cortical areas, and peak density in the central subcapsular region were not statistically significant.

\section{Lens Curvatures and Thickness}

There were no significant differences in the anterior lens surface radius $(-0.01 \pm 0.11 \mathrm{~mm})$, posterior lens surface radius $(0.07 \pm 0.13 \mathrm{~mm})(\mathrm{n}=6)$ or total axial thickness of the lens $(-0.03 \pm$ $0.04 \mathrm{~mm})(\mathrm{n}=6)$ after HBO therapy. The curvatures and thickness measurements from the Scheimpflug images were implemented into the customary thick lens formula to estimate the lens refractive power before and after treatment. Result of the calculation showed no apparent difference in lens refractive power, $-0.09 \pm 0.16 \mathrm{D}$ (range $-0.39 \mathrm{D}$ to $0.03 \mathrm{D})(\mathrm{n}=6)$. There were no significant changes in nuclear thickness, anterior cortex thickness or posterior cortex thickness following the treatment (Table 3). 


\section{Backward Scattered Light}

A small but statistically significant reduction was found in mean backscattered light after HBO therapy compared to before the therapy, $-0.4 \pm 0.8$ units (range -2.0 units to 1.0 units) ( $p=$ 0.022). The age-related trends showing an increase with age in backscattered light and nuclear optical density at the baseline visit were not changed after the treatment (Figure 2).

\section{DISCUSSION}

A significant myopic shift ( $\geq-0.50 \mathrm{D})$ occurred in $13(65 \%)$ single eyes during the study period. After three weeks of the treatment, most of the patients noticed a change in visual quality with their current correction. The best-corrected visual acuity appears to be stable during a standard course of HBO therapy. ${ }^{5,6,12}$ The myopic shift was not accompanied by any change in keratometry or axial length of the eye, indicating that the cause of the myopic shift is related to the lens. Lenticular myopia could be caused by steeper lens curvatures, increased axial lens thickness, an anterior displacement of the lens, increased refractive index of the lens, or a combination of these factors. No changes in surface shape, lens thickness or anterior chamber depth were found following treatment.

The significant changes that were found after HBO therapy were a reduction in backward scattered light and decrease in nuclear optical density, suggesting that alterations in the media of the lens caused the change in refractive status of the eye. Both backscattered light and nuclear optical density had natural higher values for older patients before and after HBO therapy. The patients participating in this study showed individual changes in myopic shifts ranging from $0.00 \mathrm{D}$ to $-1.50 \mathrm{D}$. Applying the measured lenticular parameters from the Scheimpflug images 
combined with the fixed refractive index from the Gullstrand-Emsley relaxed eye $(1.416)^{23}$ revealed no significant differences in calculated lens power after treatment. A change of the refractive index value from 1.416 to 1.424 would be sufficient to reach a lenticular power change of $1.50 \mathrm{D}$, which was the maximum shift recorded in this study. Applying a two-index lens model (Gullstrand no. 1 parameters $)^{23,24}$, there would need to be an increase in the nuclear refractive index from 1.406 to 1.412 or a decrease in the cortical refractive index from 1.386 to 1.337 to produce an increase of about $1.50 \mathrm{D}$ in equivalent power of the eye.

To explain the increase in refractive power as resulting from an increase in nuclear refractive index would appear to be inconsistent with the decline in nuclear optical density following treatment that was found in this study. The explanation for this apparent contradiction is most likely to come from the fact that the lens has a gradient of refractive index in the cortical region with a relatively constant refractive index in the nucleus. ${ }^{25,26}$ Rays of light are refracted when they encounter a change in refractive index; the greater the change or the steeper the gradient of index, the greater is the refractive power. In a gradient index lens ${ }^{25}$ structure, a relatively subtle change in the shape of the refractive index gradient will alter the equivalent refractive index of the lens. If the measured decrease in nuclear optical density does indeed indicate a decrease in nuclear refractive index, an explanation for a greater refractive power could be a steepening of the gradient index in the cortex ${ }^{25}$ and would require only subtle changes in local magnitude of refractive index. No significant differences were found in the cortical density after treatment, but the measure was averaged across a substantial cortical region and hence masked any local variations. 
The gradient refractive index of the lens is formed by the concentration and distribution of its structural proteins: the crystallins, which constitute just over a third of the wet weight of the human lens. ${ }^{27}$ Local changes in refractive index occur when the protein concentration change in that region. Since water in the lens exists as either, free water or water bound to proteins, a change in local protein concentration can also be related to an increase in the proportion of free water as bound water is released. ${ }^{28}$ The results show a significant decline in lens optical density and backscatter, which can be related to a localised change in water state. Since lens proteins are not considered to be independent scatterers,${ }^{29}$ it may be that the decrease in backscatter is caused by a tighter packing of proteins, ${ }^{30-32}$ which is not incompatible with a release of bound water.

During HBO therapy, the lens equator is exposed to an enhanced concentration of blood-born oxygen, which passes the blood-aqueous barrier. HBO exposure to bovine lenses in organ culture has been shown to cause reversible optical changes, which progress from the periphery of the lens to its centre causing a change in focal length. ${ }^{11}$ These results support the suggestion that HBO treatment causes changes in the cortical gradient. Changes in cortical refractive index gradient could also explain the occurrence of hypermetropic shifts that have been reported in patients after HBO therapy. ${ }^{12,13}$

Despite a few exceptional cases that have reported cataract formation in human eyes following HBO therapy, ${ }^{8,10}$ the myopic shifts tend to attenuate and disappear some weeks after completion of the treatment. ${ }^{6}$ Two patients in the study of Palmquist et al. were observed with a partly reversible nuclear cataract. ${ }^{10}$ If indeed variation in the lens refractive index is the cause of the 
myopic shift, the time course of the myopic shift and its reversal need to be taken into account when considering the underlying mechanism.

The Lens Opacity Meter measures diffuse changes in backward scattered light from a projected cylindrical light beam in the axial part of the lens. ${ }^{18}$ Adjusted for dilated pupils and age, the degree of overall lenticular opacification was within the defined limits of clear lenses ${ }^{18}$ for all the patients during HBO therapy (Figure 2). As the assessment was conducted through a dilated pupil with a minimum diameter of $6.00 \mathrm{~mm}$, any absorption by the iris ${ }^{33}$ would be negligible. The minimum pupil diameter appeared slightly larger after the therapy (Table 3). But larger pupils would rather release more backscattered light, ${ }^{18}$ while a reduction in scattered light occurred. Backward scattered light from a slit beam (as observed through the biomicroscope slitlamp), collect changes from a wider sectional area of the lens and are more susceptible to the location and origin of the lens changes. ${ }^{18}$ No lenses were seen with distinct cortical spoke opacities, which could artificially interfere with back projected shadows and thus affect the measurements. Hence, the small but significant decrease in backscattered light from the lens after HBO therapy could be influenced by reduced fluctuations in the gradient of the refractive index ${ }^{25}$ or by destructive interference. ${ }^{31}$

Under normal physiological conditions, a myopic shift (1.00 D) occurring over four years in the adult human eye might be the first sign of underlying cataract. ${ }^{34}$ When the lens subsequently manifests with increased turbidity and reduced transparency, structural changes may already have been underway for some time. Lenticular changes in refraction may take place long before any loss of lens transparency can be seen on gross observation in the lens. ${ }^{11}$ There might 
therefore be an early latency period during HBO therapy, in which scatter is reduced because of reorganisation of the crystalline proteins and a change in water content, before this manifests as localised aggregations of protein and formation of cataract. Most measuring devices in the normal eye care clinic are unlikely to be sufficiently sensitive to detect the variations in lenticular optical properties during the very first phase of these changes.

Improved oxygen supply to ocular ischemic tissue may reduce swelling and volume associated with low oxygen tension. Resolution of macula oedema and reduced retinal thickness has been reported in a diabetic patient during HBO therapy. ${ }^{35}$ No changes in intraocular pressure or axial length of the eye occurred in these patients after treatment, which is in line with results reported in other studies using the similar HBO treatment protocol. ${ }^{4,5,12}$

A limitation of the study is that posterior surface of the lens appeared visible only in one third of the patients because of restricted dilation of the pupil. Large pupils are determined by the contraction of the dilator pupillae muscles and the relaxation of the sphincter pupillae muscles, which are innervated by the sympathetic and parasympathetic nervous system, respectively. Hyperbaric oxygen inhalation has shown to increase parasympathetic activity in professional divers, and might thus be a contributing factor to the limited mydriasis. ${ }^{36}$ In addition, senile miosis is a well-known phenomenon ${ }^{37}$ with decrease in pupil area in later adulthood among normal subjects. All the patients in this study had reached the age of presbyopia.

In conclusion, the present study shows that the only measurable ocular change accompanying the temporary myopic shift in patients undergoing HBO therapy is a significant reduction in 
backscattered light and optical density of the lens. These findings indicate that the myopic shift is most likely caused by changes in the structure of the lens tissue, leading to subtle alterations in the refractive index gradient.

\section{ACKNOWLEDGMENTS}

The authors thank Professor Mo Jalie for his advice on ray tracing, Thomas J. T. P. van den Berg, $\mathrm{PhD}$, for useful discussions on forward scattered light measurements with the C-Quant, and Olav Hammer for excellent Nidek EAS-1000 technical support. 


\section{REFERENCES}

1. Lyne AJ. Ocular effects of hyperbaric oxygen. Trans Ophthalmol Soc U K 1978;98:66-8.

2. Anderson B, Jr, Farmer JC, Jr. Hyperoxic myopia. Trans Am Ophthalmol Soc 1978;76:11624.

3. Ross ME, Yolton DP, Yolton RL, Hyde KD. Myopia associated with hyperbaric oxygen therapy. Optom Vis Sci 1996;73:487-94.

4. Fledelius HC, Jansen EC, Thorn J. Refractive change during hyperbaric oxygen therapy. A clinical trial including ultrasound oculometry. Acta Ophthalmol Scand 2002;80:188-90.

5. Evanger K, Vaagbø G, Thorsen E, Haugen OH. Phakic and pseudophakic eyes in patients during hyperbaric oxygen therapy. Optom Vis Sci 2011;88:691-96.

6. Evanger K, Haugen $\mathrm{OH}$, Irgens $\AA$, Aanderud L, Thorsen E. Ocular refractive changes in patients receiving hyperbaric oxygen administered by oronasal mask or hood. Acta Ophthalmol Scand 2004; 82:449-53.

7. Pierscionek BK. Refractive index contours in the human lens. Exp Eye Res 1997;64:887-93.

8. Gesell LB, Trott A. De novo cataract development following a standard course of hyperbaric oxygen therapy. Undersea Hyperb Med 2007;34:389-92.

9. Truscott RJ. Age-related nuclear cataract-oxidation is the key. Exp Eye Res 2005;80:70925.

10. Palmquist BM, Philipson B, Barr PO. Nuclear cataract and myopia during hyperbaric oxygen therapy. Br J Ophthalmol 1984;68:113-7.

11. Schaal S, Beiran I, Rubinstein I, Miller B, Dovrat A. Lenticular oxygen toxicity. Invest Ophthalmol Vis Sci 2003;44:3476-84. 
12. Evanger K, Haugen OH, Aanderud L, Thorsen E, Pierscionek BK. Hypermetropia succeeded myopia after hyperbaric oxygen therapy. Optom Vis Sci 2006;83:195-8.

13. Fledelius HC, Jansen EC. Hypermetropic refractive change after hyperbaric oxygen therapy. Acta Ophthalmol Scand 2004;82:313-4.

14. Franssen L, Coppens JE, van den Berg TJ. Compensation comparison method for assessment of retinal straylight. Invest Ophthalmol Vis Sci 2006;47:768-76.

15. van den Berg TJ, Franssen L, Kruijt B, Coppens JE. History of ocular straylight measurement: A review. Z Med Phys 2013;23:6-20.

16. Piñero DP, Ortiz D, Alio JL. Ocular scattering. Optom Vis Sci 2010;87:E682-96.

17. Davies LN, Bartlett H, Mallen EA, Wolffson JS. Clinical evaluation of rebound tonometer. Acta Ophthalmol Scand 2006;84:206-9.

18. Wegener A, Hockwin O. First experience with the Interzeag lens opacity meter in measuring normal and cataractous lens. Lens Research 1988;5:183-90.

19. Wegener A, Laser-Junga H. Photography of the anterior eye segment according to Scheimpflug's principle: options and limitations - a review. Clin Experiment Ophthalmol 2009;37:144-54.

20. Scheimpflug T. Der Photoperspectograph und seine Anwendung. Photogr Korr $1906 ; 43: 516-31$.

21. Nidek Co Ltd. Nidek Anterior Eye Segment Analysis System. EAS-1000 Operators Manual. Aichi, Japan: Nidek Co Ltd, 1991.

22. Jones RL, Kratz RP. In vivo lens density measurements using the IntraOptics opacity lensmeter. J Cataract Refract Surg 1990;16:115-9.

23. Atchison DA, Smith G. Optics of the Human Eye. Oxford: Butterworth-Heinemann; 2000. 
24. Jalie M. Principles of Ophthalmic Lenses (4th Edition reprinted). London: Association of British Dispensing Opticians; 1997.

25. Pierscionek BK, Regini JW. The gradient index lens of the eye: an opto-biological synchrony. Prog Retin Eye Res 2012;31:332-49.

26. Pierscionek BK. Presbyopia and the effect of refractive index. Clin Exp Optom 1990;73:2636.

27. Van Heyningen R. The human lens. III. Some observations on the post-mortem lens. Exp Eye Res 1972;13:155-60.

28. Lahm D, Lee LK, Bettelheim FA. Age dependence of freezable and nonfreezable water content of normal human lenses. Invest Ophthalmol Vis Sci 1985;26:1162-5.

29. Delaye M, Tardieu A. Short-range order of crystalline proteins accounts for eye lens transparency. Nature 1983;302:415-7.

30. Latina M, Chylack LT, Jr, Fagerholm P, Nishio I, Tanaka T, Palmquist BM. Dynamic light scattering in the intact rabbit lens. Its relation to protein concentration. Invest Ophthalmol Vis Sci 1987;28:175-83.

31. Trokel S. The physical basis for transparency of the crystalline lens. Invest Ophthalmol $1962 ; 1: 493-501$.

32. Benedek GB. Theory of transparency of the eye. Appl Opt 1971;10:459-73.

33. Clarke MP, Pearson JC, Vernon SA, Matthews JC. Influence of pupil size on measurements made with the Lens Opacity Meter 701. Br J Ophthalmol 1990;74:526-7.

34. Brown NA, Hill AR. Cataract: the relation between myopia and cataract morphology. Br J Ophthalmol 1987;71:405-14. 
35. Averous K, Erginay A, Timsit J, Haouchine B, Gaudric A, Massin P. Resolution of diabetic macular oedema following high altitude exercise. Acta Ophthalmol Scand 2006;84:830-1.

36. Lund V, Kentala E, Scheinin H, Klossner J, Sariola-Heinonen K, Jalonen J. Hyperbaric oxygen increases parasympathetic activity in professional divers. Acta Physiol Scand 2000;170:39-44.

37. Winn B, Whitaker D, Elliot DB, Phillips NJ. Factors affecting light-adapted pupil size in normal human subjects. Invest Ophthalmol Vis Sci1994;35:1132-7.

Corresponding author:

Knut Evanger

Essilor Norge as

Hermann Foss gate 4

N-3611 Kongsberg

NORWAY

e-mail: knut.evanger@essilor.no

Reprints:

Knut Evanger

Hjortveien 15

N-3370 Vikersund

NORWAY 
Table 1. Ocular measurements listed in the order taken, the instruments and the units of measurements used.

\begin{tabular}{|c|c|c|c|}
\hline Variables & Mydriasis $^{a}$ & Instruments/Analysis & Units \\
\hline 1. Ocular refraction & No & Nidek ARK 900, Auto-refractor/keratometer & Diopters (D) \\
\hline 2. Corneal curvature radius & No & Nidek ARK 900, Auto-refractor/keratometer & Millimeters (mm) \\
\hline 3. Forward scattered light & No & Oculus C-Quant, Straylight meter & Logarithmic units (Log[s] units) \\
\hline 4. Intraocular pressure & No & Tiolat ICare, Rebound tonometer & Millimeter mercury (mmHg) \\
\hline 5. Axial length of the eye & Yes & Zeiss IOLMaster & Millimeters $(\mathrm{mm})$ \\
\hline $\begin{array}{l}\text { 6. Scheimpflug pictures: } \\
\text { Lens optical density } \\
\text { Lens surface curvatures } \\
\text { Anterior chamber depth } \\
\text { Axial lens thickness } \\
\text { Pupil diameter }\end{array}$ & Yes & $\begin{array}{c}\text { Nidek EAS-1000, Anterior segment analysis Analysis in the } \\
\text { "Desitometry (Peak)" program } \\
\text { Analysis of the "Axial Biometry" program Analysis of the "Axial } \\
\text { Biometry" program } \\
\text { Analysis of the "Axial Biometry" program } \\
\text { Analysis of the "Axial Biometry" program }\end{array}$ & $\begin{array}{l}\text { Arbitrary units }(0-255 \text { pixel grayscale units }) \\
\text { Millimeters }(1 \text { pixel }=0.026 \mathrm{~mm}) \\
\text { Millimeters }(1 \text { pixel }=0.026 \mathrm{~mm}) \\
\text { Millimeters }(1 \text { pixel }=0.026 \mathrm{~mm}) \\
\text { Millimeters }(1 \text { pixel }=0.026 \mathrm{~mm})\end{array}$ \\
\hline 7. Backward scattered light & Yes & Interzeag Lens Opacity Meter 701 & Arbitrary units (0-99 scale units) \\
\hline
\end{tabular}

a Mydriasis was achieved 40 minutes after administration of Cyclopentolate $1 \%$ eyedrops 
Table 2. Ocular refraction, biometry, light scatter and lens optical density during hyperbaric oxygen therapy.

\begin{tabular}{|c|c|c|c|c|}
\hline Variables & $\mathrm{n}$ & $\begin{array}{c}\text { Day } 1 \text { after HBO therapy } \\
\text { Mean } \pm \text { SD } \\
\text { Min (Median) Max }\end{array}$ & $\begin{array}{c}\text { Day } 19 \text { after HBO therapy } \\
\text { Mean } \pm \text { SD } \\
\text { Min (Median) Max }\end{array}$ & $\mathrm{p}^{\mathrm{a}}$ \\
\hline 1. Ocular refraction (D) & 20 & $\begin{array}{c}0.21 \pm 1.46 \\
-3.88(0.38) 3.50\end{array}$ & $\begin{array}{c}-0.37 \pm 1.53 \\
-4.88(-0.06) 2.88\end{array}$ & $<0.001$ \\
\hline Ocular refraction $(\mathrm{D})^{\mathrm{b}}$ & 6 & $\begin{array}{c}-0.19 \pm 0.57 \\
-1.13(-0.13) 0.38 \\
\end{array}$ & $\begin{array}{c}-0.83 \pm 0.81 \\
-1.75(-0.88) 0.38 \\
\end{array}$ & 0.022 \\
\hline 2. Corneal curvature radius $(\mathrm{mm})$ & 20 & $\begin{array}{c}7.74 \pm 0.33 \\
7.23(7.66) 8.24\end{array}$ & $\begin{array}{c}7.73 \pm 0.33 \\
7.23(7.62) 8.24\end{array}$ & 0.160 \\
\hline 3. Forward light scatter $(\log [s])$ & 20 & $\begin{array}{c}1.16 \pm 0.16 \\
0.84(1.19) 1.47\end{array}$ & $\begin{array}{c}1.15 \pm 0.12 \\
0.93(1.14) 1.40\end{array}$ & 0.653 \\
\hline 4. Intraocular pressure (mmHg) & 20 & $\begin{array}{c}14.1 \pm 3.6 \\
8.0(13.7) 23.7 \\
\end{array}$ & $\begin{array}{c}13.4 \pm 3.2 \\
9.3(13.0) 23.3 \\
\end{array}$ & 0.109 \\
\hline 5. Axial length of the eye $(\mathrm{mm})$ & 20 & $\begin{array}{c}23.36 \pm 1.09 \\
21.44(23.46) 25.06\end{array}$ & $\begin{array}{c}23.36 \pm 1.08 \\
21.43(23.45) 25.06\end{array}$ & 0.427 \\
\hline \multicolumn{5}{|l|}{ 6. Scheimpflug pictures: } \\
\hline Subcapsular density (units), 1 pixel $^{\mathrm{c}}$ & 20 & $\begin{array}{c}74.5 \pm 27.5 \\
22.8(72.3) 150.5\end{array}$ & $\begin{array}{c}73.3 \pm 28.4 \\
24.0(69.0) 142.0\end{array}$ & 0.696 \\
\hline Subcapsular density (units), 2 pixels $^{c}$ & 20 & $\begin{array}{c}83.1 \pm 30.5 \\
29.5(81.8) 162.5\end{array}$ & $\begin{array}{c}79.0 \pm 28.7 \\
32.0(67.8) 145.0\end{array}$ & 0.257 \\
\hline Subcapsular density (units), 3 pixels ${ }^{c}$ & 20 & $\begin{array}{c}78.1 \pm 27.8 \\
31.0(79.8) 138.0\end{array}$ & $\begin{array}{c}75.6 \pm 26.4 \\
34.0(75.3) 126.0\end{array}$ & 0.525 \\
\hline Anterior cortex density (units) ${ }^{d}$ & 20 & $\begin{array}{c}56.8 \pm 13.9 \\
38.5(54.0) 85.5\end{array}$ & $\begin{array}{c}55.6 \pm 15.5 \\
29.5(55.5) 89.5\end{array}$ & 0.411 \\
\hline Nuclear density (units) ${ }^{e}$ & 20 & $\begin{array}{c}65.1 \pm 13.7 \\
46.0(63.0) 90.0\end{array}$ & $\begin{array}{c}62.3 \pm 14.0 \\
34.5(61.0) 85.0\end{array}$ & 0.009 \\
\hline Nuclear density (units) ${ }^{f}$ & 20 & $\begin{array}{c}60.7 \pm 12.8 \\
43.0(59.8) 83.0\end{array}$ & $\begin{array}{c}58.5 \pm 13.3 \\
33.0(57.3) 79.0\end{array}$ & 0.027 \\
\hline Posterior cortex density (units) ${ }^{g}$ & 6 & $\begin{array}{c}51.7 \pm 3.5 \\
48.5(50.8) 57.5 \\
\end{array}$ & $\begin{array}{c}48.2 \pm 5.4 \\
42.0(47.0) 56.0\end{array}$ & 0.094 \\
\hline 7. Backward light scatter (units) & 20 & $\begin{array}{c}19.2 \pm 3.7 \\
13.0(19.3) 27.3\end{array}$ & $\begin{array}{c}18.7 \pm 3.8 \\
12.7(19.0) 28.3\end{array}$ & 0.022 \\
\hline
\end{tabular}

$\mathrm{SD}$, standard deviation; D, diopters; mm, millimeter; Min, minimum; Max, Maximum

a Paired samples t-test

${ }^{b}$ Objective refraction for the six patients of which the posterior lens radius were available

${ }^{c}$ Distance from anterior capsular apex (1 pixel $=0.026 \mathrm{~mm}$ )

${ }^{d}$ Mean optical density within oval areas ( $40 \times 15$ pixels) in anterior cortex

e Mean optical density within circular areas (35 x 35 pixels) in nucleus

${ }^{f}$ Mean optical density within oval areas ( $75 \times 35$ pixels) in nucleus

9 Mean optical density within oval areas ( $40 \times 15$ pixels) in posterior cortex for the six patients the posterior lens surface radius were available 
Table 3. Lens surface curvatures, axial lens thickness and calculated lens power during hyperbaric oxygen therapy.

\begin{tabular}{|c|c|c|c|c|}
\hline Variables & $\mathrm{n}$ & $\begin{array}{c}\text { Day } 1 \text { after HBO therapy } \\
\text { Mean } \pm \text { SD } \\
\text { Min (Median) Max }\end{array}$ & $\begin{array}{c}\text { Day } 19 \text { after HBO therapy } \\
\text { Mean } \pm \text { SD } \\
\text { Min (Median) Max }\end{array}$ & $p^{a}$ \\
\hline \multicolumn{5}{|l|}{ 6. Scheimpflug pictures: } \\
\hline Anterior lens surface radius (mm) & $\mathrm{n}=20$ & $\begin{array}{c}11.09 \pm 1.09 \\
8.75(11.30) 12.87\end{array}$ & $\begin{array}{c}11.08 \pm 1.04 \\
8.79(11.30) 12.55\end{array}$ & 0.617 \\
\hline Anterior lens surface radius $(\mathrm{mm})^{\mathrm{b}}$ & $n=6$ & $\begin{array}{c}11.82 \pm 0.62 \\
10.95(11.81) 12.56\end{array}$ & $\begin{array}{c}11.82 \pm 0.62 \\
11.00(11.82) 12.55\end{array}$ & 0.767 \\
\hline Anterior lens surface power (D) & $\mathrm{n}=6$ & $\begin{array}{c}6.67 \pm 0.35 \\
6.26(6.66) 7.18\end{array}$ & $\begin{array}{c}6.66 \pm 0.34 \\
6.26(6.65) 7.15\end{array}$ & 0.720 \\
\hline Posterior lens surface radius $(\mathrm{mm})$ & $n=6$ & $\begin{array}{c}7.98 \pm 0.24 \\
7.61(7.98) 8.31\end{array}$ & $\begin{array}{c}8.06 \pm 0.33 \\
7.69(8.00) 8.64\end{array}$ & 0.241 \\
\hline Posterior lens surface power (D) & $\mathrm{n}=6$ & $\begin{array}{c}10.35 \pm 0.31 \\
9.94(10.35) 10.85\end{array}$ & $\begin{array}{c}10.27 \pm 0.40 \\
9.56(10.32) 10.75\end{array}$ & 0.225 \\
\hline Total lens thickness (mm) & $\mathrm{n}=6$ & $\begin{array}{c}4.22 \pm 0.18 \\
4.03(4.21) 4.45\end{array}$ & $\begin{array}{c}4.18 \pm 0.18 \\
3.91(4.17) 4.37\end{array}$ & 0.179 \\
\hline Anterior cortex thickness (mm) & $\mathrm{n}=6$ & $\begin{array}{c}1.13 \pm 0.10 \\
1.02(1.11) 1.30\end{array}$ & $\begin{array}{c}1.13 \pm 0.09 \\
1.06(1.09) 1.29\end{array}$ & 0.662 \\
\hline Nuclear thickness (mm) & $n=6$ & $\begin{array}{c}2.31 \pm 0.11 \\
2.11(2.32) 2.44\end{array}$ & $\begin{array}{c}2.28 \pm 0.11 \\
2.13(2.29) 2.40\end{array}$ & 0.193 \\
\hline Posterior cortex thickness (mm) & $n=6$ & $\begin{array}{c}0.78 \pm 0.15 \\
0.63(0.72) 0.98\end{array}$ & $\begin{array}{c}0.69 \pm 0.16 \\
0.48(0.67) 0.95\end{array}$ & 0.319 \\
\hline Anterior chamber depth (mm) & $\mathrm{n}=20$ & $\begin{array}{c}2.88 \pm 0.30 \\
2.23(2.87) 3.45\end{array}$ & $\begin{array}{c}2.89 \pm 0.30 \\
2.27(2.88) 3.47\end{array}$ & 0.089 \\
\hline Pupil diameter (mm) & $n=20$ & $\begin{array}{c}7.37 \pm 0.72 \\
6.00(7.38) 8.88\end{array}$ & $\begin{array}{c}7.45 \pm 0.75 \\
6.10(7.42) 8.89\end{array}$ & 0.005 \\
\hline Calculated lens power (D)c & $\mathrm{n}=6$ & $\begin{array}{c}16.81 \pm 0.21 \\
16.57(16.85) 17.12\end{array}$ & $\begin{array}{c}16.73 \pm 0.24 \\
16.50(16.69) 17.14\end{array}$ & 0.248 \\
\hline
\end{tabular}

SD, standard deviation; D, diopters; mm, millimeter; Min, minimum; Max, Maximum

a Paired samples t-test

${ }^{b}$ Anterior lens surface radius for the six patients the posterior lens surface radius were available

${ }^{c}$ Calculation of lens power uses the lens refractive index $(n=1.416)^{23}$ from Gullstrand-Emsley relaxed eye 


\section{FIGURE LEGENDS}

Figure 1. Scheimpflug images showing (A) optical density within oval areas in the cortex, and circular and oval areas in the lens nucleus, $(\mathbf{B})$ anterior lens surface curvature, and (C) anterior chamber depth and axial thickness of the lens.

Figure 2. Backward scattered light (A) and nuclear optical density within oval areas (B) plotted against age of the patients. Dark gray dots and dotted regression lines before, and light gray dots and solid line after HBO therapy are shown. The arrows show the direction and magnitude of the changes. Only light gray dots appear when no changes occur. 


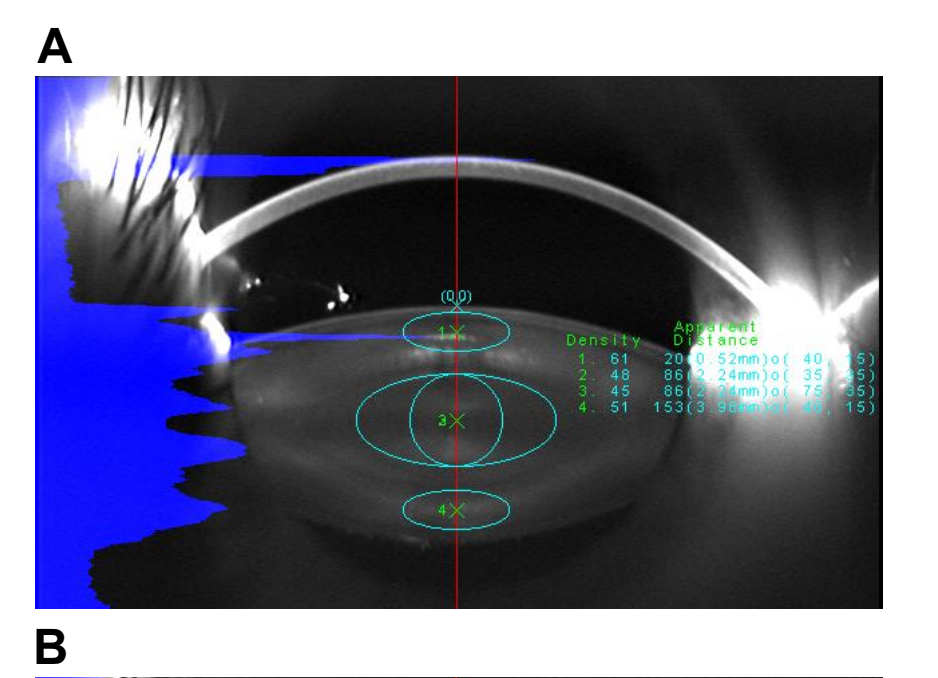

B

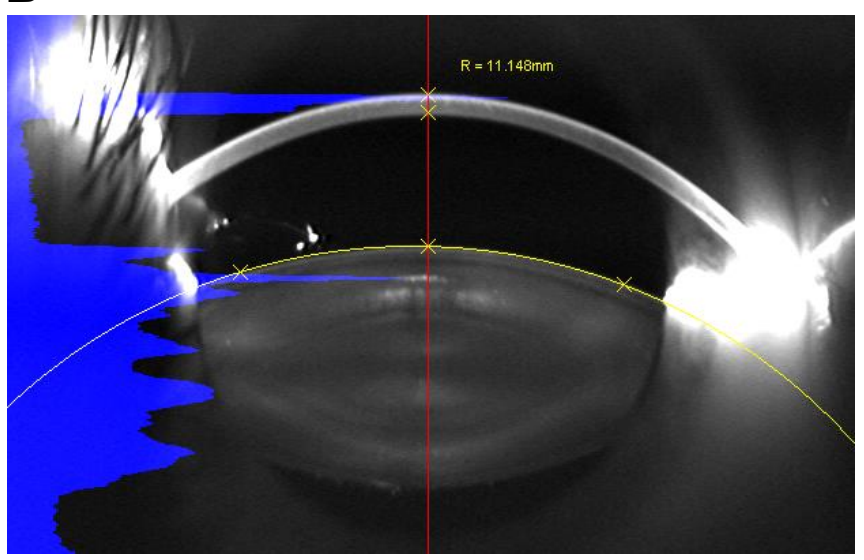

C

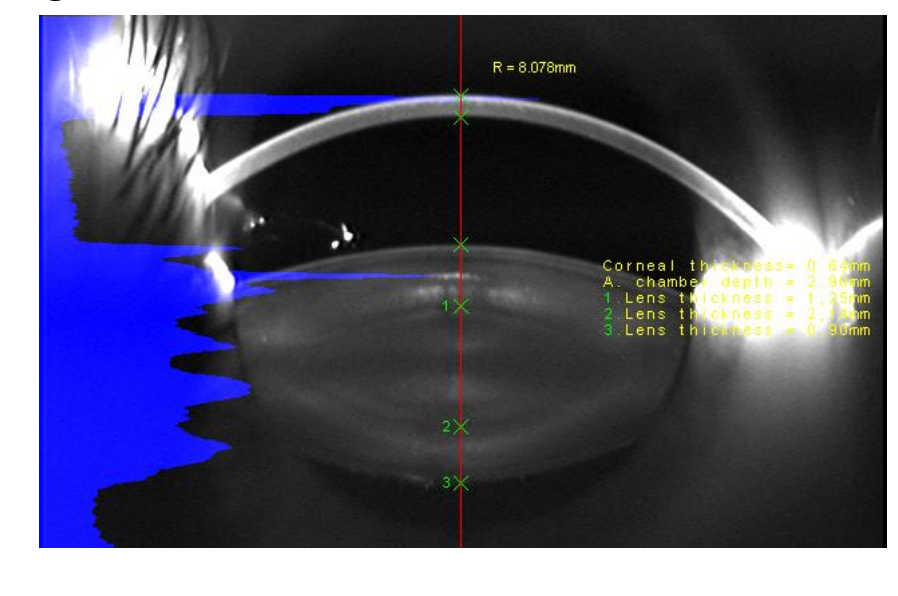

Figure 1

Figure $1 A-C$ color finalKAZ

A

.

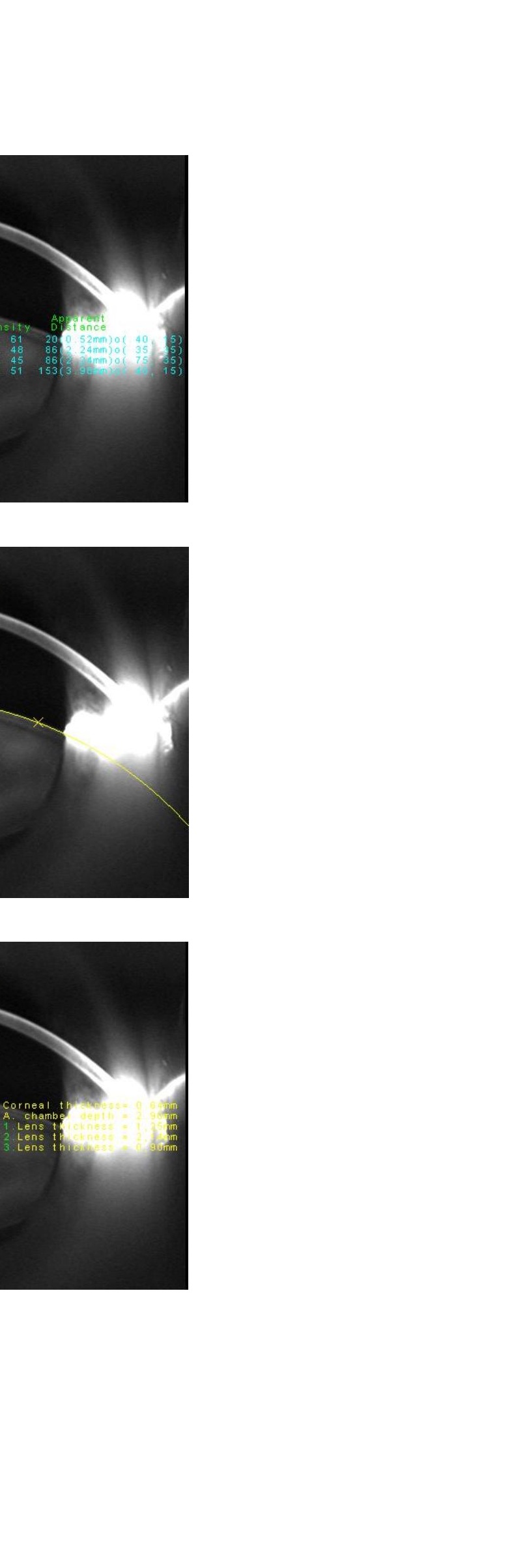

(

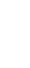

Figure $1 A-C$ color finalKAZ
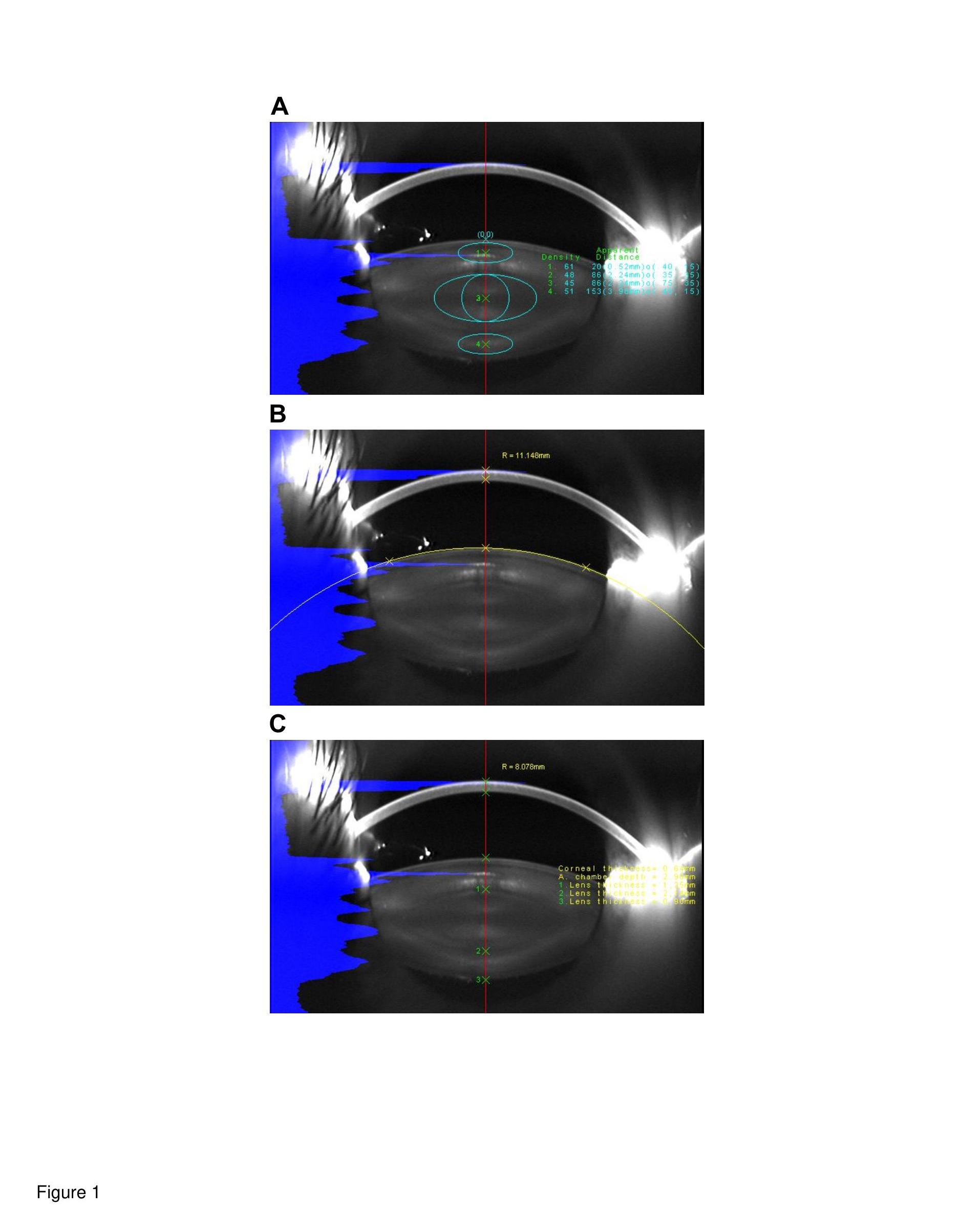
Figure $2 A-B$ finalKAZ

Click here to download Figure: OVS14614 figure 2A-B combinedKAZ.tif

A

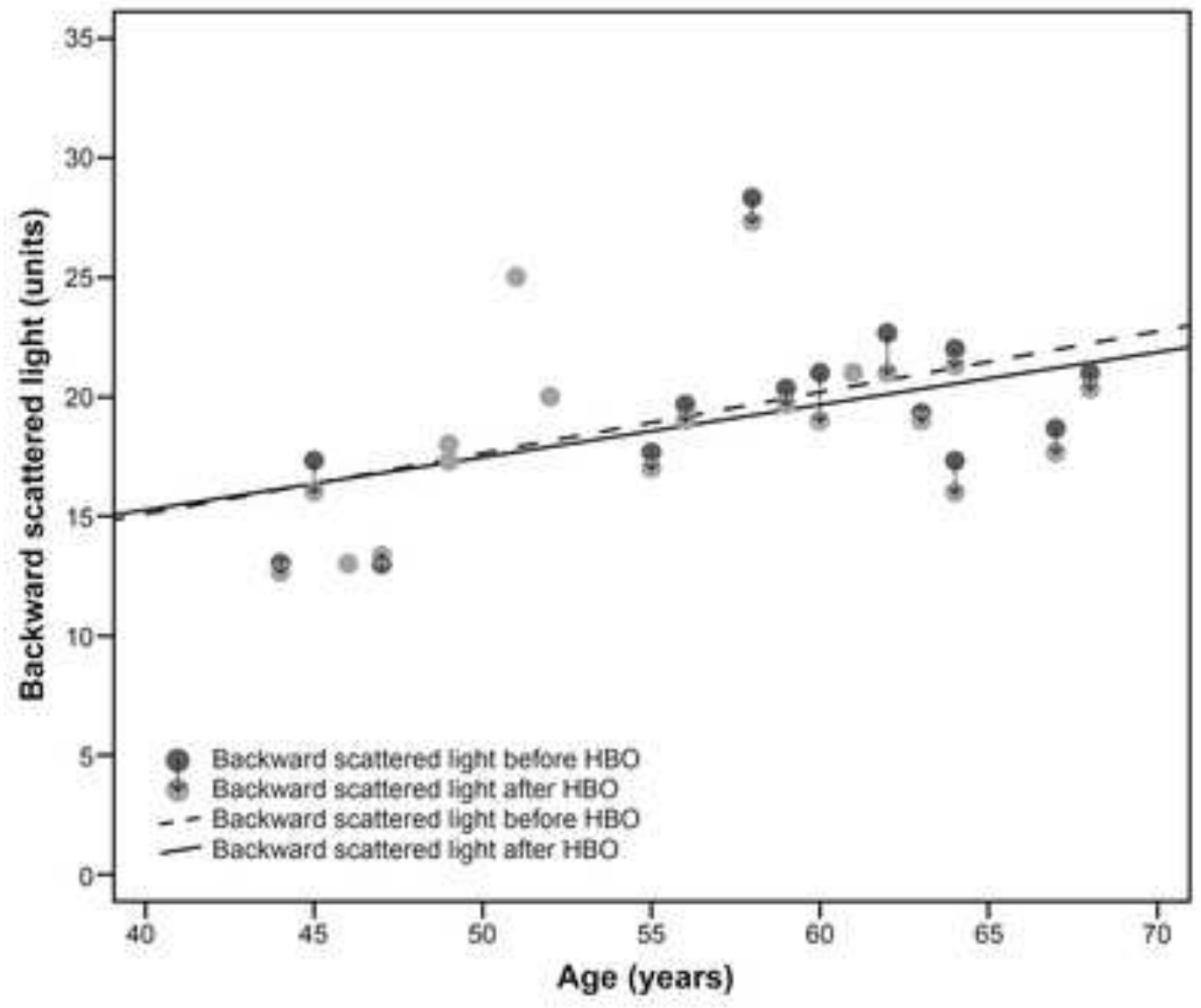

B

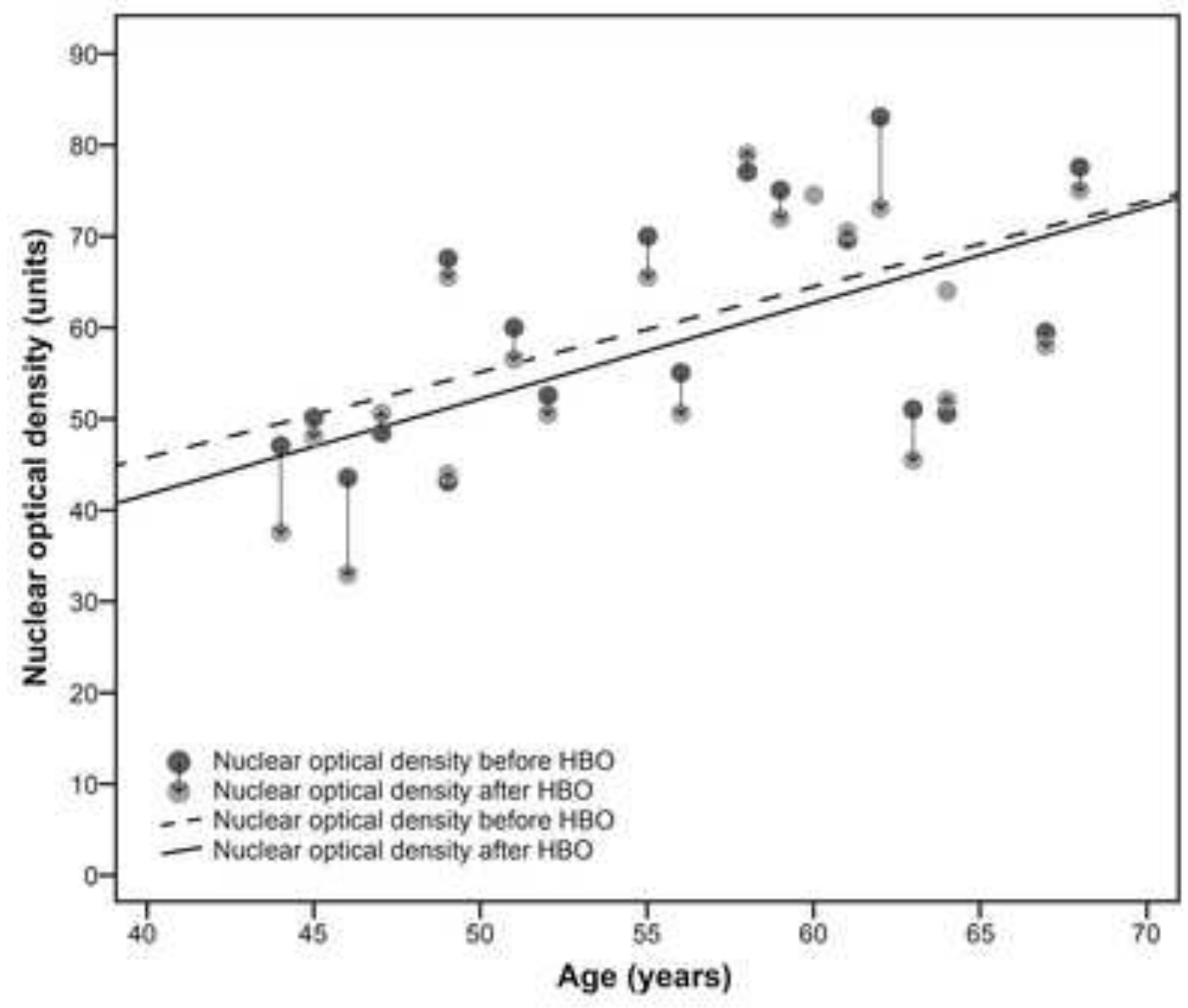

